\title{
Introduction to the special issue on advances in the psychology of workplace coaching
}

Article

Accepted Version

Bozer, G. and Jones, R. J. ORCID: https://orcid.org/00000001-7329-0502 (2021) Introduction to the special issue on advances in the psychology of workplace coaching. Applied Psychology, 70 (2). pp. 411-419. ISSN 1464-0597 doi: https://doi.org/10.1111/apps.12305 Available at https://centaur.reading.ac.uk/96622/

It is advisable to refer to the publisher's version if you intend to cite from the work. See Guidance on citing.

To link to this article DOI: http://dx.doi.org/10.1111/apps.12305

Publisher: Wiley

All outputs in CentAUR are protected by Intellectual Property Rights law, including copyright law. Copyright and IPR is retained by the creators or other copyright holders. Terms and conditions for use of this material are defined in the End User Agreement.

www.reading.ac.uk/centaur 
Central Archive at the University of Reading

Reading's research outputs online 


\title{
Introduction to the Special Issue on
}

\section{Advances in the Psychology of Workplace Coaching}

\begin{abstract}
This article introduces a special issue of Applied Psychology: An International Review that focuses on recent advances in the psychology of workplace coaching. In the initial section, we briefly describe the current state of workplace coaching research, and we then outline the aims and objectives that had driven our motivation in editing this special issue. We set out two objectives for this special issue. Firstly, to ensure that each of the contributions started with relevant theoretical framework, and secondly, that the papers in this special issue utilized rigorous research design and methodology. In the next section we provide an overview of each of the five articles making up the special issue, detailing their respective contributions to advancing workplace coaching research and theory. We conclude with recommendations for future workplace coaching research, building on the contributions in this special issue. We propose scholars should focus on three key areas: future coaching research should adopt a 'start with theory' approach; that rigorous research design and methodology is prioritized, specifically in relation to utilizing multiple data sources and increasing the range of objective (hard) data as coaching outcome measures; and for coaching scholars to pay attention to and explore non-significant effects.
\end{abstract}

Keywords: workplace coaching; applied psychology; theoretical frameworks; input factors; process factors; contextual factors; coaching outcomes; coaching effectiveness. 


\section{Introduction to the Special Issue on}

\section{Advances in the Psychology of Workplace Coaching}

There has been extensive growth in the academic literature related to workplace coaching, including executive, leadership and business coaching over the past three decades (Jones, Woods, \& Guillaume, 2016). Workplace coaching is described as a one-to-one custom-tailored, learning and development intervention that uses a collaborative, reflective, goal-focused relationship provided to all levels of employees by external or internal coaching practitioners who have no formal supervisory authority over the coachee (Bozer \& Jones, 2018). Recent meta-analyses have established that coaching is an effective development tool (e.g., Burt \& Talati, 2017; Graßmann, Schölmerich, \& Schermuly, 2020; Jones et al., 2016) and as such research has shifted from simply considering the effect of coaching towards research that explores the mechanisms, processes and factors that determine effectiveness, and explain how the desired change following coaching occurs. Two necessary requirements of research with this focus is that it is based on a theoretically solid foundation and is conducted utilizing rigorously robust research methods.

Until recently, the workplace coaching literature was dominated by practitioner-led research, published predominately in niche coaching journals and 'grey literature' (see Bozer \& Jones (2018) for a comprehensive review); this led many scholars to regard workplace coaching as a practice-based field. However, recent publications in high-ranking scientific journals indicate a shift is occurring in the literature on workplace coaching, with a move towards scientific rather than practitioner led research (e.g., Athanasopoulou \& Dopson, 2018; Bachkirova \& Borrington, 2019; Blackman, Moscardo, \& Gray, 2016; Bozer \& Delegach, 2019; Bozer \& Jones, 2018; De Haan, Gray, \& Bonneywell, 2019; Graßmann et al., 2020; Jones et al., 2016). This shift aligns with a broader trend in applied psychology towards rigorous evaluations of workplace interventions (e.g., O’Connell, O’Shea, \& 
Gallagher, 2016). It is this important shift that has driven our motivation for this special issue on the advances in the psychology of workplace coaching. We hope that the timely publication of this special issue will positively contribute to shaping the direction of workplace coaching research into a field that is widely regarded as being scientifically rigorous. We firmly believe that applied psychology theory can offer key theoretical frameworks and important insights for investigating the factors, mechanisms, and processes which can explain how and why coaching works. This theory-based knowledge is timely and essential to ensure a maximized and sustained impact of this popular learning and development intervention.

In workplace coaching research, we now have countless examples of interesting phenomena for which no theory (or at best under-developed theory) has been provided. Early research has established, for example, the importance of the coachee's commitment to change for coaching outcomes (e.g., Kombarakaran, Yang, Baker, \& Fernandes, 2008); that a trusting, confidential relationship between coach and coachee is important for coaching outcomes (e.g., De Haan, Culpin, \& Curd, 2011); that the neutrality of the coach is essential (James-Ward, 2013); that an important element of the coaching process is the feedback provided to the coachee by the coach (e.g., Rekalde, Landeta, \& Albizu, 2015), and we could go on. Overall, for each of these observed phenomena recorded in the coaching literature, we have very little theorizing as to why these components are important. We know that they make a difference, however we do not have clear theories that explain why and how they make a difference. Consequently, our first objective in publishing this special issue was to ensure that each contribution starts with a relevant theoretical framework(s). Shaw (2017) advocates a 'start with theory' approach, arguing that it offers advantages to our scholarship including more refined, accurate, and comprehensive construct definitions; strong alignment between construct definitions and measurement and a robust study design including the 
features necessary for testing the underlying theoretical mechanisms. We believe that for workplace coaching research to advance to the next stage, we, as coaching scholars, need to take heed of the 'start with theory' message. We are pleased that all of the five papers in the collection of diverse papers on workplace coaching in our special issue, share a 'start with theory` approach. Specifically, each article adopts an established psychology theory and constructs and applies them to the workplace coaching context. For example, Fontes and Dello Russo (2021) apply psychological capital (Luthans, 2002) and goal-setting theory (Locke \& Latham, 1990), Schermuly Wach, Kirschbaum and Wegge (2021) use transactional stress theory (Lazarus \& Folkman, 1984) and Lai and Smith's (2021) research is informed by social identity theory (Tajfel \& Turner, 1985).

The second objective of our special issue was that the collection of papers would implement rigorous research design and methodology. In this context, the articles include a number of key features, such as operationalizing well-defined variables, thorough and appropriate data collection and measurement strategies, and valid statistical or qualitative analyses. These features are all essential to reducing the risks of biased results, so that ultimately, a solid evidence base can be produced. The research studies in our special issue all meet the demanding requirements of a stringent scientific research, so that they can be regarded as 'low risk' studies (Grover \& Furnham, 2016). For example, studies in our special issue include two randomized controlled trials in realistic workplace settings (Fontes \& Dello Russo, 2021; Jones, Woods, \& Zhou, 2021), hard objective measures (Schermuly et al., 2021), and the incorporation of multi-stakeholder data (Fontes \& Dello Russo, 2021; Jones et al., 2021; Kotte, Diermann, Rosing, \& Möller, 2021; Lai \& Smith, 2021).

In this special issue we present five papers from an international field of scholars who have responded to our call to establish a stronger connection between research in applied psychology and workplace coaching by conducting theoretically sound, methodologically 
robust research. We believe that the studies in this special issue contribute to the generational transition that has occurred in the workplace coaching literature over the last decade, moving from a research that is concerned with the question: 'does coaching work?' and 'what types of outcomes does it generate?', towards research that is concerned with the question: 'how and why does coaching work?' Specifically, this special issue provides important insights into, and understanding of, the factors, mechanisms, and processes associated with workplace coaching outcomes.

In the first article, Jones, Woods, and Zhou, explore how differences between individual coachees impact on coaching effectiveness, as reflected in coachee job performance. Drawing on the attribute-treatment-interaction framework from the training and learning literature, Jones et al. conduct a randomized controlled trial in a UK-based nonprofit organization to examine the interaction effects of individual coachee differences, namely, the 'Big Five' personality traits, core self-evaluations, and goal orientation, on coachee's performance improvement. By theorizing and examining how coachee input factors interact with coaching intervention features, the rigorous experimental design in this study improves our understanding of who is more likely to benefit from coaching, and why.

In the second article, Fontes and Dello Russo investigate the role of coachee psychological capital (PsyCap) in workplace coaching outcomes. Drawing on the PsyCap theoretical construct (e.g., Luthans, 2002; Luthans, Avolio, Avey, \& Norman, 2007), the authors suggest that PsyCap can be used as a mediator to explain how a coaching intervention exerts its effects. Following the principles of goal-setting theory (e.g., Locke \& Latham, 1990; Seijts \& Latham, 2005) and conservation of resources theory (e.g., Hobfoll, Halbesleben, Neveu, \& Westman, 2018), the authors design a coaching intervention that aims to enhance coachee PsyCap as a means to achieve coachee job attitudinal changes and performance improvement. The proposed coaching intervention is tested empirically through 
a randomized controlled trial among the employees of a digital marketing agency in Portugal. In addition to the theorizing and empirical examination of PsyCap as a mediating mechanism in coaching effectiveness, this study responds to important methodological concerns raised in previous research. Specifically, this study complements coachee self-report ratings with organizational multi-source feedback data that are collected at three time points (pre-post-and four months upon coaching completion).

The third article, by Lai and Smith, aims to improve understanding of the factors that promote a three-way joint coaching identity between coach, coachee and organizational stakeholders. The authors perform multi-perspective in-depth interviews with UK-based coaches, coachees, and organizational stakeholders, focusing on the critical incidents drawn from the personal coaching experience of the interviewees. The authors use social identity theory (e.g., Tajfel \& Turner, 1985), which draws on the notion of workplace coaching relationships as a group-based identity, thus providing a framework for analyzing negotiations between coach, coachee, and organizational stakeholders with the ultimate objective to reach identity alignment. Consequently, this study expands the dyadic conceptualization of the coach-coachee working alliance to focus on coaching relationships as a group-based affiliation. This group-based affiliation is shaped by multiple stakeholders who generate a wider social space that facilitates critical coaching processes such as contracting, trust building, collaboration, and change motivation.

In the fourth article, Kotte, Diermann, Rosing, and Möller focus on the emerging domain of entrepreneurial coaching (EC), which is increasingly used to support entrepreneurs at different stages of their businesses. The authors introduce a conceptual EC framework that is based on multi-perspective interview data collected from early-stage entrepreneur coachees and coaches in Germany. Consistent with input-process-output frameworks of workplace coaching (e.g., Ely et al., 2010; Greif, 2013; Joo, 2005), and training evaluation frameworks 
(e.g., Kirkpatrick, 1994; Kraiger, Ford, \& Salas, 1993), the proposed EC framework identifies input, process, contextual factors, and outcomes. This study advances workplace coaching research in two aspects, first by focussing on the specific context of entrepreneurial coaching that is targeted at early-stage entrepreneurs, this study responds to recent calls to move beyond the 'one size fits all' assumption by differentiating coaching for specific target-groups (e.g., Bozer \& Jones, 2018; Cooper, 2019). Secondly, this study contributes to EC theory by defining and mapping distinct EC characteristics and comparing them with closely related developmental interventions that are used frequently in the entrepreneurial context, including consulting and mentoring, and by positioning EC within the general forms of coaching (i.e. workplace, and executive coaching).

The final article, is a research note by Schermuly, Wach, Kirschbaum, and Wegge, and focuses on coaching a specific target group of insolvent entrepreneurs. In the context that business insolvency is an extreme stressor for entrepreneurs, the authors draw on the transactional stress theory (e.g., Lazarus \& Folkman, 1984) as a framework for coaching intervention to improve coping resources and their proposed health-related outcomes. The authors conduct a pre-post-test-within-subject design study to examine the effect of coaching on coping resources, health, and cognitive performance in insolvent entrepreneurs. Drawing on the theoretical construct of working alliance, which is rooted in psychotherapy (e.g., Bordin, 1979) and was recently supported as explanatory mechanism in coaching literature (e.g., Graßmann et al., 2020), these authors propose the coach-coachee working alliance as a moderator between coaching intervention and improvements in the proposed outcomes. This article makes a notable contribution to the field by integrating objective outcome measures (i.e., cortisol and cortisone stress hormones, and a cognitive performance test) that add to the external validity of the findings. Similar to Kotte et al. (2021), the authors respond to the call for taking a closer look at coaching as a context-sensitive intervention by examining the 
impact of coaching on a specific target group in a specific context, namely, coachee entrepreneurs who face business insolvency.

To close this introductory note to our special issue on the advances in the psychology of workplace coaching, we provide three recommendations for future research. We hope that our recommendations will guide researchers in building further on the contributions made in the papers in this issue. Firstly, we urge workplace coaching scholars to continue the work presented in our special issue and to ensure that future coaching research adopts a 'start with theory' approach. We propose that a significant contribution can be made in explaining the underlying mechanisms of coaching phenomena by applying established theory. Importantly, scholars should take on board the observation by Shepherd and Sutcliffe (2011) that a simple theory is a better theory. Theories should be testable; therefore it is important that they do not contain any summative units (Dubin, 1969). Summative units, which are global, complex units that bring together a number of different properties in a single description, are found far too often in the coaching literature; common offenders include 'client-coach relationship' (Kilburg, 2001) and 'coach characteristics' (Joo, 2005). These units often mean a great deal, although much of this is ill defined or even unspecified. For these reasons, Dubin (1969) concludes that summative units have no place in theories as they cannot be directly tested. We propose that what is now needed, is for coaching research to include simple, testable theory that has strong explanatory power to increase our understanding of the underlying processes in coaching.

Secondly, based on the studies in our special issue, we prioritise research design and methodology in future workplace coaching research. An important consideration for future research is the collection of multiple sources of data among key stakeholders in the coachee's environment (e.g., coach, line manager, subordinates, peers, human resource development personnel) to overcome or reduce the risk of bias associated with self-reported ratings. This 
recommendation becomes highly important as qualitative studies (e.g., De Haan, 2019; Lai \& Smith, 2021; Myers \& Bachkirova, 2018) demonstrate how the multi-purpose and multifaceted nature of coaching is reflected in varied agendas and objectives among coaching stakeholders in the three-way joint coaching alliance (i.e., coach, coachee, sponsor organization). Another important consideration that can further strengthen research rigor and increase the range of coaching measures is collecting objective (hard) data that complements the subjective data. We anticipate that this recommendation will become increasingly feasible as wearable technology and digital forms of data collection become more accessible and widely used throughout society (e.g., monitors to measure sleep quality, heart rate and physical activity). Moreover, given recent advances in tracking and diagnostic instruments, capturing the dynamic effects and longitudinal patterns and trends in coaching outcomes over and beyond specific points in time (i.e. pre-during-post coaching) becomes viable and valuable measurement and assessment strategies for future quantitative research.

Finally, we encourage scholars to pay close attention to and explore non-significant effects. In the five studies in our special issue, we noticed that some of the most interesting contributions came from the discussion of these non-significant effects. For example, Jones et al. (2021) explore the non-significant effects of coaching in relation to supervisor ratings of coachee performance. They explore these non-significant effects in relation to the importance of utilizing a control group in coaching intervention research and the ability of the supervisor to provide accurate performance ratings. Fontes and Dello Russo (2021) discuss the lack of a mediating role of psychological capital on changes in job performance following coaching. They propose that this may be due to the need for more time for behavioural changes such as these to unfold. Finally, Schermuly et al. (2021) explored the non-significant effects of coaching on stress hormones and propose that future research should utilize measures of both long-term stress and short-term fluctuations in stress. While we appreciate that any discussion 
of non-significant findings must be tentative in nature, we do suggest that such discussions can highlight trends in non-significant findings across studies that will both help inform theory building and highlight potential interesting avenues for further exploration. We hope that scholars who will continue to pay attention to and explore non-significant effects will be duly supported by editors and reviewers, so that a full and healthy debate of all research findings, whether those are significant or not is encouraged.

\section{References}

Athanasopoulou, A., \& Dopson, S. (2018). A systematic review of executive coaching outcomes: Is it the journey or the destination that matters the most? The Leadership Quarterly, 29(1), 7088.

Bachkirova, T., \& Borrington, S. (2019). Old wine in new bottles: Exploring pragmatism as a philosophical framework for the discipline of coaching. Academy of Management Learning \& Education, 18(3), 337-360.

Blackman, A., Moscardo, G., \& Gray, D. E. (2016). Challenges for the theory and practice of business coaching: A systematic review of empirical evidence. Human Resource Development Review, 15(4), 459-486.

Bordin, E. S. (1979). The generalisability of the psychoanalytic concept of the working alliance. Psychotherapy: Theory, Research and Practice, 16(3), 252-260.

Bozer, G., \& Delegach, M. (2019). Bringing context to workplace coaching: A theoretical framework based on uncertainty avoidance and regulatory focus. Human Resource Development Review, 18(3), 376-402.

Bozer, G., \& Jones, R. J. (2018). Understanding the factors that determine workplace coaching effectiveness: A systematic literature review. European Journal of Work and Organizational Psychology, 27(3), 342-361. 
Burt, D., \& Talati, Z. (2017). The unsolved value of executive coaching: A meta-analysis of outcomes using randomised control trial studies. International Journal of Evidence Based Coaching and Mentoring, 15(2), 17-24.

Cooper, S. E. (2019). Introduction to the special issue on coaching elite performers. Consulting Psychology Journal: Practice and Research, 71(2), 63-71.

De Haan, E. (2019). A systematic review of qualitative studies in workplace and executive coaching: The emergence of a body of research. Consulting Psychology Journal: Practice and Research, 71(4), 227-248.

De Haan, E., Culpin, V., \& Curd, J. (2011). Executive coaching in practice: What determines helpfulness for clients of coaching? Personnel Review, 40(1), 24-44.

De Haan, E., Gray, D. E., \& Bonneywell, S. (2019). Executive coaching outcome research in a field setting: A near-randomized controlled trial study in a global healthcare corporation. Academy of Management Learning \& Education, 18(4), 581-605.

Dubin, R. (1969). Theory building: A practical guide to the construction and testing of theoretical models. New York: The Free Press.

Ely, K., Boyce, L. A., Nelson, J. K., Zaccaro, S. J., Hernez-Broome, G., \& Whyman, W. (2010). Evaluating leadership coaching: A review and integrated framework. The Leadership Quarterly, 21(4), 585-599.

Fontes, A., \& Dello Russo, S. (2021). An experimental field study on the effects of coaching: The mediating role of psychological capital. Applied Psychology, 70(2).

Graßmann, C., Schölmerich, F., \& Schermuly, C. C. (2020). The relationship between working alliance and client outcomes in coaching: A meta-analysis. Human Relations, 73(1), 35-58.

Greif, S. (2013). Conducting organizational-based evaluations of coaching and mentoring programs. In J. Passmore, D.B. Peterson, and T. Freire (Eds.) The Wiley-Blackwell handbook of the psychology of coaching and mentoring (pp. 445-470). Chichester, UK: Wiley-Blackwell. 
Grover, S., \& Furnham, A. (2016). Coaching as a developmental intervention in organisations: A systematic review of its effectiveness and the mechanisms underlying it. PLOS ONE, 11(7).

Hobfoll, S. E., Halbesleben, J., Neveu, J. P., \& Westman, M. (2018). Conservation of resources in the organizational context: The reality of resources and their consequences. Annual Review of Organizational Psychology and Organizational Behavior, 5, 103-128.

James-Ward, C. (2013). The coaching experience of four novice principals. International Journal of Mentoring and Coaching in Education, 2(1), 21-33.

Jones, R. J., Woods, S. A., \& Guillaume, Y. R. F. (2016). The effectiveness of workplace coaching: A meta-analysis of learning and performance outcomes from coaching. Journal of Occupational and Organizational Psychology, 89(2), 249-277.

Jones, R. J., Woods, S. A., \& Zhou, Y. (2021). The effects of coachee personality and goal orientation on performance improvement following coaching: A controlled field experiment. Applied Psychology, 70(2).

Joo, B-K. (2005). Executive coaching: A conceptual framework from an integrative review of practice and research. Human Resource Development Review, 4(4), 462-488.

Kilburg, R. R. (2001). Facilitating intervention adherence in executive coaching: A model and methods. Consulting Psychology Journal: Practice and Research, 53(4), 251-267.

Kirkpatrick, D. L. (1994). Evaluating training programs: The four levels. San Francisco, CA: Berrett-Koehler.

Kotte, S., Diermann, I., Rosing, K., \& Möller, H. (2021). Entrepreneurial coaching: A twodimensional framework in context. Applied Psychology, 70(2).

Kraiger, K., Ford, J. K., \& Salas, E. (1993). Application of cognitive, skill-based, and affective theories of learning outcomes to new methods of training evaluation. Journal of Applied Psychology, 78(2), 311-328. 
Kombarakaran, F. A., Yang, J. A., Baker, M. N., \& Fernandes, P. B. (2008). Executive coaching: It works! Consulting Psychology Journal: Practice and Research, 60(1), 78-90.

Lai, Y.-L., \& Smith, H. (2021). An investigation of the three-way joint coaching alliance: A social identity theory perspective. Applied Psychology, 70(2).

Lazarus, R. S., \& Folkman, S. (1984). Stress, appraisal, and coping. New York: Springer.

Locke, E., \& Latham, G. (1990). A theory of goal setting and task performance. Englewood Cliffs, NJ: Prentice Hall.

Luthans, F. (2002). The need for and meaning of positive organizational behaviour. Journal of Organizational Behaviour, 23(6), 695-706.

Luthans, F., Avolio, B. J., Avey, J. B., \& Norman, S. M. (2007). Positive psychological capital: Measurement and relationship with performance and satisfaction. Personnel Psychology, $60(3), 541-572$.

Myers, A. C., \& Bachkirova, T. (2018). Towards a process-based typology of workplace coaching: An empirical investigation. Consulting Psychology Journal: Practice and Research, 70(4), $297-317$.

O’Connell, B. H., O’Shea, D., \& Gallagher, S. (2016). Enhancing social relationships through positive psychology activities: A randomised controlled trial. The Journal of Positive Psychology, 11(2), 149-162.

Rekalde, I., Landeta, J., \& Albizu, E. (2015). Determining factors in the effectiveness of executive coaching as a management development tool. Management Decision, 53(8), 1677-1697.

Schermuly, C. C., Wach, D., Kirschbaum, C., \& Wegge, J. (2021). Coaching of insolvent entrepreneurs and the change in coping resources, health, and cognitive performance. Applied Psychology, 70(2).

Seijts, G. H., \& Latham, G. P. (2005). Learning versus performance goals. When should each be used? Academy of Management Perspectives, 19(1), 124-131. 
Shaw, J. D. (2017). Advantages of starting with theory. Academy of Management Journal, 60(3), 819-822.

Shepherd, D. A., \& Sutcliffe, K. M. (2011). Inductive top-down theorizing: A source of new theories of organization. Academy of Management Review, 36(2), 361-380.

Tajfel, H., \& Turner, J. C. (1985). The social identity theory of group behavior. In S. Worchel \& W.G. Austin (Eds.), Psychology of intergroup relations. Chicago: Nelson-Hall. 